\title{
Rho A/Rho kinase: human umbilical artery mRNA expression in normal and pre eclamptic pregnancies and functional role in isoprostane-induced vasoconstriction
}

\author{
Anne M Friel ${ }^{1,2}$, Donal J Sexton ${ }^{1}$, Michael W O'Reilly ${ }^{1}$, Terry J Smith ${ }^{2}$ and John J Morrison ${ }^{1,2}$ \\ ${ }^{1}$ Department of Obstetrics and Gynaecology, National University of Ireland, Galway, Clinical Science Institute, \\ University College Hospital, Newcastle Road, Galway, Ireland and ${ }^{2}$ National Centre for Biomedical Engineering \\ Science, National University of Ireland, Galway, Ireland
}

Correspondence should be addressed to J J Morrison; Email: john.morrison@nuigalway.ie

\begin{abstract}
Pre eclampsia represents a state of increased or prolonged vasoconstriction, partially linked to the potent vasocontractile effect of isoprostanes. The process of Rho A-mediated calcium sensitisation is inherent to a state of prolonged contractility in many smooth muscle types. The aim of this study was (1) to investigate mRNA expression levels of Rho A and Rho kinase isoforms (I and II) in the umbilical artery from normotensive and pre eclamptic women and (2) to determine whether the effects of two isoprostanes, 8-iso prostaglandin $\mathrm{F}_{2 \alpha}$ (8-iso PGF2 $\alpha$ ) and 8-iso prostaglandin $\mathrm{E}_{2}$ (8-iso $\mathrm{PGE}_{2}$ ), on umbilical artery tone, were mediated via the Rho kinase pathway. Real-time RT-PCR using primers for Rho A, ROCK I and ROCK II was performed on total RNA isolated from umbilical artery specimens obtained from normotensive and pre eclamptic women. The effects of both isoprostanes $(n=6)$ (in the absence and presence of the specific Rho kinase inhibitor Y-27632), on umbilical artery tone were measured, and compared with control recordings. Rho A mRNA expression levels were significantly lower in umbilical artery samples obtained from pre eclamptic women $(n=4)$ in comparison to those from normotensive women $(n=6)(P<0.05)$. ROCK I and ROCK II mRNA levels were similar in both vessel types $(P>0.05)$. Both isoprostanes exerted a significant concentration-dependent vasocontractile effect $(n=7)(P<0.001)$ on umbilical artery. For 8-iso PGE $_{2}$, this effect was antagonised by Y-27632 $(n=6)(P<0.01)$. The significant reduction of Rho A mRNA levels in umbilical arteries from pregnancies complicated by pre eclampsia may serve to counteract the diminished perfusion associated with the pathophysiology of pre eclampsia. The vasocontractile effect of 8-iso $\mathrm{PGE}_{2}$ in pre eclampsia may in part be mediated via the Rho kinase pathway.

Reproduction (2006) 132 169-176
\end{abstract}

\section{Introduction}

Pre eclampsia is a hypertensive disorder affecting 3-5\% of all pregnancies and is a leading cause of maternal and foetal morbidity and mortality (Walker 2000). It is associated with foetal growth restriction, premature birth and low birth-weight babies (Walker 2000, Byrne \& Morrison 2001). Pre eclampsia is characterised by intense and prolonged vasospasm. This ultimately leads to elevated systemic vascular resistance and the clinical manifestation of maternal hypertension, which may result in decreased perfusion to organs including the kidney, uterus, placenta, liver and brain (Roberts \& Cooper 2001). Central to this condition are mechanisms that regulate vascular smooth muscle contractility, namely signalling pathways that regulate vasoconstriction in the systemic circulation.
Research has indicated that the process of calcium sensitisation (increase in smooth muscle tension and/or phosphorylation of myosin light chains at a constant $\left[\mathrm{Ca}^{2+}\right]_{i}$ by inhibition of myosin light chain phosphatase $(\mathrm{MLCP})$ ), is of major importance in regulating the state of vasoconstriction of vascular smooth muscle (Somlyo \& Somlyo 2000). It is now apparent that the small G protein, Rho A is associated with inhibition of MLCP (Uehata et al. 1997, Kunihiko et al. 1999). Although the precise mechanism of action is unknown, two target proteins of Rho A, ROCK I and its isoform ROCK II, which are collectively known as Rho kinases, have a major role in Rho A-mediated calcium sensitisation. Upon activation, they enhance Rho-mediated calcium sensitisation and hence smooth muscle contractility. It is now clear that this Rho kinase pathway plays a central role in the pathogenesis of hypertension in animal 
models, in humans and in various situations of increased peripheral vascular resistance observed in hypertensive disorders (Chitaley et al. 2001) and the prolonged enhanced arterial vasoconstriction in heart failure (Hisaoka et al. 2001). There is no information pertaining to the role of the Rho pathway in foeto-placental vasculature during normal pregnancy or in pregnancies complicated by pre eclampsia. The foeto-placental unit is apparently not innervated (Fox \& Khong 1990) and hence the regulation of blood flow to the placenta must depend on structural changes, the influence of vasoactive factors and local signalling mechanisms.

It is known that isoprostanes, metabolites of arachidonic acid, are closely linked to the severe vasoconstriction associated with pre eclampsia (Walsh et al. 2000) and can exert their action in part via the Rho kinase pathway (Janssen et al. 2001). Isoprostanes are implicated in the pathogenesis of a wide variety of human disorders and are used extensively as markers of oxidative stress (Roberts \& Morrow 2000), with markedly increased levels reported in disorders associated with increased vascular constriction such as in angina (Cipollone et al. 2000), heart failure (Mallat et al. 1998), pulmonary hypertension (Christman 1998) and pre eclampsia (Barden et al. 1996, Staff et al. 1999, Walsh et al. 2000). To date, there are minimal data outlining the potential role of RhoA/Rho kinase in foetoplacental vasculature. First in normal pregnancies and pregnancies complicated by pre eclampsia, and secondly in the vasoconstrictor actions of isoprostanes. Therefore, the aim of this study was twofold. First, to investigate the mRNA expression levels of Rho A, ROCK I and ROCK II in human umbilical artery in normal pregnancies and pregnancies complicated by pre eclampsia. Secondly, to investigate the effects of two isoprostanes, 8-iso $\mathrm{PGF}_{2 \alpha}$ and 8-iso $\mathrm{PGE}_{2}$, on human umbilical artery tone and to determine if their effects were mediated via the rho kinase pathway.

\section{Materials and Methods}

\section{Tissue collection}

Patient recruitment took place in the Department of Obstetrics and Gynaecology, University College Hospital, Galway, Ireland. Ethical Committee approval for tissue collection was obtained from the Research Ethics Committee at University College Hospital Galway and patient recruitment was by written informed consent. For mRNA expression studies, sections of umbilical cord were excised from the proximal segment of the cord (i.e. nearest placental attachment) immediately after vaginal delivery or elective caesarean section at term, from normotensive pregnancies and pregnancies complicated by pre eclampsia. Umbilical artery was dissected free of Warton's jelly, immediately snap frozen in liquid nitrogen and stored at $-80{ }^{\circ} \mathrm{C}$. The normotensive group were non-proteinuric patients with uncomplicated pregnancies. The criteria for pre eclampsia were as follows: at least two separate blood pressure readings $>$ $140 / 90 \mathrm{mmHg}$, and the presence of +1 protein or more, by dipstick analysis on more than one occasion (Fleming et al. 2000). Women with known pre existing cardiac or renal disease were excluded from the study. For organ tissue bath studies, sections of umbilical cord excised from the proximal segment of the cord immediately after elective caesarean section were placed in KrebsHenseleit physiologic salt solution, $\mathrm{pH} 7.4$, containing: $4.7 \mathrm{mmol} \mathrm{I}^{-1} \mathrm{KCl}, 118 \mathrm{mmol} \mathrm{I}^{-1} \mathrm{NaCl}, 1.2 \mathrm{mmol} \mathrm{I}^{-1}$ $\mathrm{Mg}_{2} \mathrm{SO}_{4}, 1.2 \mathrm{mmol} \mathrm{I}{ }^{-1} \mathrm{CaCl}_{2}, 1.2 \mathrm{mmol} \mathrm{I}{ }^{-1} \mathrm{KPO}_{4}$, $25 \mathrm{mmol} \mathrm{I}^{-1} \mathrm{NaHCO}_{3}$ and $11 \mathrm{mmol} \mathrm{I}{ }^{-1}$ glucose. Indomethacin $\left(10 \mu \mathrm{mol} \mathrm{^{-1 } )}\right.$ was also added to the Krebs-Henseleit solution to prevent generation of cyclooxygenase metabolites of arachidonic acid. Cord was stored at $4{ }^{\circ} \mathrm{C}$ and used within $12 \mathrm{~h}$ of collection.

\section{RNA extraction and RT}

Total RNA was isolated using TRIzol reagent (Life Technologies) (Chomczynski 1993). All RNA samples were DNA-free treated (Ambion Inc., Austin, TX, USA) and checked by standard RT-PCR to ensure that RNA used for real-time fluorescence RT-PCR contained no contaminating genomic DNA. One microgram of RNA (DNA-free treated) (Ambion Inc.) was reverse transcribed into cDNA for use as a template for PCR. The RNA samples were then denatured at $65^{\circ} \mathrm{C}$ for $10 \mathrm{~min}$. RT was performed at $42{ }^{\circ} \mathrm{C}$ for $60 \mathrm{~min}$ in a reaction volume of $20 \mu$ l containing the following: oligo dT primer (500 ng), Moloney murine leukaemia virus (M-MLV) RT buffer $\left(50 \mathrm{mmol} \mathrm{I^{-1 }}\right.$ Tris- $\mathrm{HCl} \mathrm{pH} 8.3,75 \mathrm{mmol} \mathrm{I^{-1 }} \mathrm{KCl}$, $3 \mathrm{mmol} \mathrm{I}^{-1} \mathrm{MgCl}_{2}, 10 \mathrm{mmol} \mathrm{I}^{-1}$ dithiothreitol (DTT) (Promega), diethylpyrocarbonate (DEPC)-treated water (BDH, Dorset, England), dNTPs $\left(0.2 \mathrm{mmol} \mathrm{I}^{-1}\right)$ (Promega) and $200 \mathrm{U}$ M-MLV reverse transcriptase (Promega). Reverse transcriptase activity was stopped by heating samples at $65^{\circ} \mathrm{C}$ for $10 \mathrm{~min}$. Control RNA samples, in which no RT enzyme was added, were included to confirm that no genomic DNA contamination was present.

\section{PCR}

Five microlitres of the RT reaction mixture was then used in the subsequent PCR. PCR was performed in a final volume of $50 \mu \mathrm{l}$ containing $1.5 \mathrm{mmolI}^{-1} \mathrm{MgCl}_{2}$, $20 \mathrm{mmoll}^{-1}$ Tris- $\mathrm{HCl}, 50 \mathrm{mmol} \mathrm{I}^{-1} \mathrm{KCl} \mathrm{pH} 8.3$ (Life Technologies), $1.25 \mathrm{U}$ Taq DNA polymerase (Life Technologies), $40 \mu^{m o l I^{-1}}$ dNTPs (Promega) and 0.2 pmol $^{-1}$ each sense and antisense primer. cDNA amplification was carried out by an initial denaturation step of $5 \mathrm{~min}$ at $95^{\circ} \mathrm{C}$ followed by 45 cycles of denaturation at $94{ }^{\circ} \mathrm{C}$ for $20 \mathrm{~s}$, annealing at $55^{\circ} \mathrm{C}$ for $45 \mathrm{~s}$ and elongation at $72{ }^{\circ} \mathrm{C}$ for $45 \mathrm{~s}$. Five microlitres of 
each PCR product were then separated by gel electrophoresis on a $1.5 \%$ agarose gel. Products were separated alongside a 2-log DNA molecular weight ladder for sizing. Primers used were designed to published DNA and mRNA sequences from GenBank as previously reported (Moran et al. 2002, Friel et al. 2005) (Table 1).

\section{One step real-time fluorescence RT-PCR}

One step RT-PCR using specific primers for Rho A, ROCK I and ROCK II was performed on total RNA isolated from umbilical artery using the LightCycler (Roche Diagnostics). Reagents from the RNA Amplification kit SYBR Green I (Roche Diagnostics) were used throughout the experiment. Standard curves containing a certain number of cDNA copies were generated for each of Rho A $\left(1 \times 10^{9}\right.$ cDNA copies, $1 \times 10^{7}$ cDNA copies, $1 \times 10^{6}$ cDNA copies), ROCK I $\left(1 \times 10^{8}\right.$ cDNA copies, $1 \times 10^{6}$ cDNA copies, $1 \times 10^{5}$ cDNA copies) and ROCK II $\left(1 \times 10^{8}\right.$ cDNA copies, $1 \times 10^{6}$ cDNA copies, $1 \times 10^{5}$ cDNA copies) genes. Copy number/ $\mu$ l cDNA was calculated according to the following formula, available from the Roche Lightcycler website (Curley et al. 2004):

\section{$6 \times 10^{23}[$ copies $/ \mathrm{mol}] \times$ concentration $[\mathrm{g} / \mu \mathrm{l}]$ \\ $=$ amount $[$ copies $/ \mu \mathrm{l}]$ molecular weight $[\mathrm{g} / \mathrm{mol}]$}

500 ng of the DNA-free treated RNA samples, in which no genomic contamination was present, were used in the subsequent one step real-time fluorescence RT-PCR. This reaction was performed in a final volume of $20 \mu \mathrm{l}$ containing $6 \mathrm{mmol} \mathrm{MgCl}_{2} \mathrm{I}^{-1}, 0.4 \mu \mathrm{l}$ enzyme mix, $4 \mu \mathrm{l}$ reaction mix, $2 \mu \mathrm{l}$ resolution solution, (Roche Diagnostics $\mathrm{GmbH}$ ), and $0.3 \mu \mathrm{mol} \mathrm{I}^{-1}$ of each sense and antisense primer. The final volume of $20 \mu \mathrm{l}$ was achieved using sterile water (Roche Diagnostics $\mathrm{GmbH}$ ). RT was carried out at $55^{\circ} \mathrm{C}$ for $30 \mathrm{~min}$. cDNA amplification was carried out by an initial denaturation step at $95^{\circ} \mathrm{C}$ for $30 \mathrm{~s}$, followed by 45 cycles of denaturation at $95^{\circ} \mathrm{C}$ with a $5 \mathrm{~s}$ hold time, annealing at $55^{\circ} \mathrm{C}$ with a $10 \mathrm{~s}$ hold time and elongation at $72{ }^{\circ} \mathrm{C}$ with a $15 \mathrm{~s}$ hold time. The temperature transition rate for the elongation step was $2{ }^{\circ} \mathrm{C} / \mathrm{s}$. The temperature transition rate for each step was $20^{\circ} \mathrm{C} / \mathrm{s}$ unless otherwise stated. Fluorescence data was acquired at the end of each PCR cycle, as previously described (Friel et al. 2005). The LightCycler Software version 3 (fit-points method, Roche), calculated cDNA copy numbers for each gene, generated from their respective amplification curve crossing points (point at which exponential amplification begins) and generated standard curve. This point is equivalent to fluorescence data plotted on the logarithmic scale. Generated cDNA copy numbers for Rho A, ROCK I and ROCK II were then normalised to the housekeeping gene $\beta$-actin. Melting curve analysis was performed by an initial denaturation step of $95^{\circ} \mathrm{C}$, cooling to $65^{\circ} \mathrm{C}$ for $10 \mathrm{~s}$ and finally gradually increasing the temperature to $95^{\circ} \mathrm{C}$. Fluorescence was measured continually during the melting curve cycle.

$10 \mu \mathrm{l}$ of each PCR product were then separated by gel electrophoresis on a $1.5 \%(\mathrm{w} / \mathrm{v})$ agarose gel. Products were separated alongside a 2-log DNA molecular weight ladder for sizing. cDNA copy numbers for Rho A, ROCK I and ROCK II generated automatically via the LightCycler from their respective standard curves were normalised to the housekeeping gene $\beta$-actin.

\section{Umbilical artery tissue bath experiments}

Human umbilical artery was dissected free of Warton's jelly and cut into transverse rings, approximately 3-5 mm in length. Rings were suspended on stainlesssteel hooks and mounted in organ tissue baths under $2 \mathrm{~g}$ tension as previously described (Dennedy et al. 2002, Ravikumar et al. 2004). The tissue baths contained $10 \mathrm{ml}$ of Krebs-Henseleit physiologic salt solution maintained at $37{ }^{\circ} \mathrm{C}, \mathrm{pH} 7.4$ and gassed continuously with $95 \% \mathrm{O}_{2} /$ $5 \% \mathrm{CO}_{2}$. Individual rings were allowed to equilibrate for at least 90 min, during which time the Krebs-Henseleit physiologic salt solution was changed every $15 \mathrm{~min}$. After the equilibration period, rings were challenged with $60 \mathrm{mM} \mathrm{KCl}$. Once the maximum response to $\mathrm{KCl}$ was achieved, rings were washed and allowed to equilibrate for $20 \mathrm{~min}$, to allow base-line to be reached again. The $\mathrm{KCl}$ challenge was repeated three times. After $40 \mathrm{~min}$ of the final $\mathrm{KCl}$ washout, either 8-iso $\mathrm{PGF}_{2 \alpha}$ or 8-iso $\mathrm{PGE}_{2}$ were added in a cumulative manner, at 20 min intervals, at concentrations of 1,10 and $100 \mathrm{nmol} \mathrm{I}^{-1}$ and 1 and $10 \mu \mathrm{mol} \mathrm{I}{ }^{-1}$. The mechanical response of tissues was measured by calculation of the

Table 1 Primers used for standard RT-PCR and real-time fluorescence RT-PCR.

\section{RT-PCR Primers}

Human Rho A

(Accession Code: L25080)

Human ROCK I

(Accession Code: XM_008814)

Human ROCK II

(Accession Code: XM_002676)

Human $\beta$-actin

(Accession Code: M10277)

Sense
Antisense
Sense
Antisense
Sense
Antisense
Sense
Antisense

Antisense

\author{
5'-CTCATAGTCTTCAGCAAGGACCAGTT-3' \\ 5'-ATCATTCCGAAGATCCTTCTTATT-3' \\ 5'-GAAGAAAGAGAAGCTCGAGAAGAAGG-3' \\ 5'-ATCTTGTAGCTCCCGCATCTGT-3' \\ 5'-AATTCACTGTGTTTCCCTGAAGATA- $3^{\prime}$ \\ $5^{\prime}$-TTCATTTTTCCTTGATTGTATGGAA-3' \\ $5^{\prime}$-CAACTCCATCATGAAGTGTGAC- $3^{\prime}$ \\ 5'-GCCATGCCAATCTCTCATCTTG-3'
}


mean amplitude of contraction for 20-min periods using the PowerLab hardware unit and Chart version 3.6 software (AD Instruments, Hastings, UK). The mean amplitude of contraction for the first 20 min (following the 40-min period after the final $\mathrm{KCl}$ washout) was calculated and this value served as a control. Antagonism of the effects of 8-iso $\mathrm{PGF}_{2 \alpha}$ and 8-iso $\mathrm{PGE}_{2}$ were investigated by addition of the rho kinase inhibitor, Y-27632 $\left(10 \mu \mathrm{mol} \mathrm{I}^{-1}\right) 30 \mathrm{~min}$ prior to the addition of 8iso $\mathrm{PGF}_{2 \alpha}$ or 8-iso $\mathrm{PGE}_{2}$. Control strips were simultaneously run with bath exposure to vehicle, but without addition of drug. The effects of 8-iso $\mathrm{PGF}_{2 \alpha}$, 8-iso $\mathrm{PGE}_{2}$ alone and with Y-27632 were expressed in terms of $g$ tension generated.

\section{Drugs and solutions}

All the chemicals were purchased from Sigma-Aldrich, unless otherwise stated. 8-iso $\mathrm{PGF}_{2 \alpha}$ and 8-iso $\mathrm{PGE}_{2}$ were obtained from Cayman Chemical, Ann Arbor, MI, USA. A stock solution $\left(10 \mathrm{mmol}^{-1}\right)$ of 8-iso $\mathrm{PGF}_{2 \alpha}$ or 8-iso $\mathrm{PGE}_{2}$ was prepared in dimethylsulphoxide (DMSO). Series of dilutions were made with KrebsHenseleit physiologic salt solution on the day of experimentation and maintained at room temperature for the duration of the experiment. Y-27632 was kindly donated by Welfide Corporation, Osaka, Japan. A stock solution $\left(10 \mathrm{mmol} \mathrm{I}^{-1}\right)$ of $\mathrm{Y}-27632$ was made with deionised water. Series of dilutions were made with Krebs-Henseleit physiologic salt solution on the day of experimentation. A stock solution $\left(100 \mathrm{mmoll}^{-1}\right)$ of indomethacin was made in DMSO. Fresh KrebsHenseleit physiologic salt solution was made daily.

\section{Statistical analysis}

For the mRNA expression study, normalised cDNA copy numbers for each transcript, between both vessel types, were compared using the Student's $t$-test. For the organ tissue bath study, calculated mean g tension for control rings and rings exposed to either 8-iso $\mathrm{PGF}_{2 \alpha}$ (alone or with Y-27632) and 8-iso $\mathrm{PGE}_{2}$ (alone or with Y-27632) were compared using Student's $t$ test. A P value of $<0.05$ for the Student's $t$ test was considered to be statistically significant. Comparisons of $g$ tension, for each bath concentration of 8-iso $\mathrm{PGF}_{2 \alpha}$ (alone or with Y-27632) and 8-iso $\mathrm{PGE}_{2}$ (alone or with Y-27632) were performed using ANOVA followed by Sheffe post hoc comparison where appropriate. The statistical package SPSS for Windows version 11 (SPSS Inc., Chicago, Illinois, USA) was used for these statistical calculations. The concentration of drug resulting in half the maximal effect (i.e. the $\mathrm{EC}_{50}$ ) was measured and represented in pharmacological terms as its appropriate $-\log _{10}$ value (i.e. $\left.\log _{10} \mathrm{EC}_{50}\right)$, which is also known as the $p D_{2}$ value. The mean maximum contractile (MMC) effect is the maximum contractile effect produced by the highest concentration of drug (i.e. $10 \mu \mathrm{mol} \mathrm{I}^{-1}$ ). Curve fitting was performed with the package Prism (Graphpad Software, San Diego, USA).

\section{Results}

\section{Tissue samples}

For the mRNA expression study, umbilical cords were obtained from six normotensive women and four pre eclamptic women after delivery. All the six normotensive women had elective caesarean sections. The reasons for elective caesarean section were previous caesarean section $(n=5)$ and breech presentation $(n=1)$. The mean patient age (years) \pm s.E.M. was $35.67 \pm 2.06$; median gestation 39 weeks (range 38-40); parity 0 $(n=1), 1(n=4), 3(n=1)$. Among the four pre eclamptic women, one had an elective caesarean section. The reason for the caesarean section was breech presentation. The mean patient age (years) \pm s.E.M. was $32.25 \pm$ 3.90; median gestation 37.5 weeks (range 36-39); parity $0(n=2), 1(n=1), 2(n=1)$.

For organ tissue bath studies umbilical arteries were obtained from a total of 12 women following delivery. Among these 12 women, eight underwent elective caesarean section. The reasons for elective caesarean section included previous caesarean section $(n=2)$, breech presentation $(n=3)$, patient request $(n=1)$, high head $(n=1)$ and macrosomia $(n=1)$. The mean patient age (years) \pm s.E.M. was $33.50 \pm 2.08$; median gestation 39.5 weeks (range $38-41)$; parity $0(n=6), 1(n=4), 2$ $(n=1), 3(n=1)$.

\section{Standard RT-PCR}

$\beta$-actin, Rho A, ROCK I and ROCK II mRNA expression was detected in all samples (Fig. 1). Amplification of umbilical artery cDNA with the $\beta$-actin primer set yielded a $377 \mathrm{bp}$ PCR product. Amplification with the Rho A primer set resulted in a 309 bp PCR product and amplification with ROCK I and ROCK II primers yielded 369 and $390 \mathrm{bp}$ products. These products were

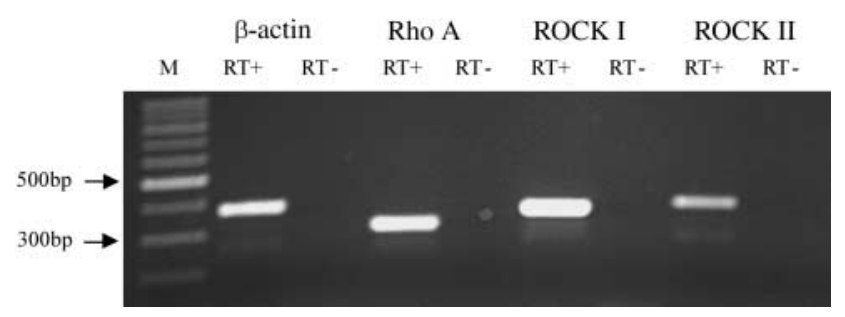

Figure 1 Representative agarose gel stained with ethidium bromide demonstrating expression of $\beta$-actin, Rho A, ROCK I and ROCK II in human umbilical artery (normotensive). Reverse transcriptase-negative controls (RT -) for both genes are shown alongside reverse transcriptase-positive $(\mathrm{RT}+)$ PCR products. $M$ represents the 2-log DNA molecular weight ladder. 
sequenced (MWG-Biotech Ltd, London UK) and results verified that they were the appropriate parts of the $\beta$-actin, Rho A, ROCK I and ROCK II gene sequences. PCR of the reverse transcriptase negative controls (RT-) showed no amplification confirming the absence of significant genomic DNA contamination. Similarly, the PCR negative control (no cDNA template) showed no amplification. Therefore, RNA in which no genomic contamination was present was used for subsequent quantitative real-time fluorescence RT-PCR.

\section{One-step fluorescence RT-PCR}

To compensate for any undue experimental error, analyses of each gene, for both vessel types, were performed in triplicate. The mean values of these experiments were used for statistical analysis. The four primer sets yielded RT-PCR products of the expected sizes (data not shown). All the patients showed expression of $\beta$-actin, Rho A, ROCK I and ROCK II mRNA. Standard curves generated for each of the genes under investigation were used to determine their respective transcript number, per $0.5 \mu \mathrm{g}$ total RNA, in both vessel types studied. Using the LightCycler Software version 3 (fit-points method), calculated cDNA copy numbers for each gene were generated from their respective amplification curve crossing points (point at which exponential amplification begins) as previously described (Friel et al. 2005). A representative recording of fluorescence plotted on the logarithmic scale corresponding to Rho A amplification in umbilical artery is shown in Fig. 2. The melting peak analyses of Rho A, ROCK I and ROCK II showed specificity of product amplification (data not shown).

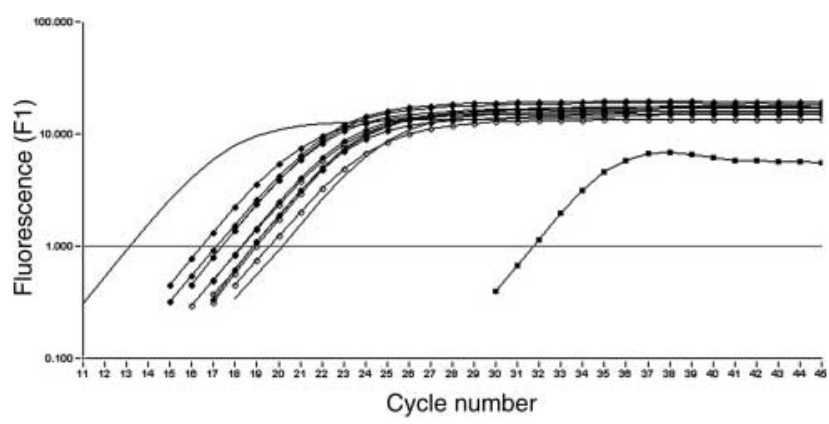

Figure 2 Quantitative real-time fluorescence RT-PCR amplification curve for Rho A mRNA expression in human umbilical artery (both normal and pre eclamptic). Fluorescence is plotted on the $y$-axis and PCR cycle number on the $x$-axis. Continuous lines represent the Rho A cDNA standards $\left(1 \times 10^{9}\right.$ and $1 \times 10^{7}$ cDNA copy numbers). Closed circles represent normal samples $(n=6)$, open circles represent pre eclamptic samples $(n=4)$ and closed squares represent the water control.
Table 2 cDNA copy numbers \pm s.E.M. for Rho A, ROCK I, ROCK II and $\beta$-actin in human umbilical artery (both normal and pre eclamptic).

\begin{tabular}{lcc}
\hline Gene & \multicolumn{1}{c}{ Normal } & Pre eclamptic \\
\hline Rho A & $7.0 \times 10^{7} \pm 7.6 \times 10^{6}$ & $4.8 \times 10^{7 *} \pm 4.5 \times 10^{6}$ \\
ROCK I & $1.3 \times 10^{7} \pm 8.7 \times 10^{5}$ & $1.0 \times 10^{7} \pm 1.9 \times 10^{6}$ \\
ROCK II & $5.2 \times 10^{7} \pm 1.1 \times 10^{7}$ & $3.0 \times 10^{7} \pm 6.7 \times 10^{5}$ \\
$\beta$-actin & $2.8 \times 10^{8} \pm 4.5 \times 10^{7}$ & $4.1 \times 10^{8} \pm 9.6 \times 10^{7}$ \\
\hline
\end{tabular}

Values presented are means \pm S.E.M.

$* P<0.05$ vs Normal.

\section{Umbilical artery expression}

$\beta$-actin mRNA expression did not significantly differ between normotensive and pre eclamptic umbilical arteries (Table 2), which indicated that $\beta$-actin was suitable as a housekeeping gene for this vessel type. Therefore, cDNA copy numbers for Rho A, ROCK I and ROCK II were normalised to the $\beta$-actin gene for the determination of their absolute cDNA copy numbers per $0.5 \mu \mathrm{g}$ total RNA. Comparisons of cDNA copy numbers, between both groups, for Rho A, revealed that Rho A mRNA expression was significantly downregulated in artery obtained from pre eclamptic women in comparison to that measured in artery obtained from normotensive women $(P<0.05)$. The cDNA copy numbers (per $0.5 \mu \mathrm{g}$ total RNA) \pm the S.E.M. for Rho $A$ were: (normal) $7.0 \times 10^{7} \pm 7.6 \times 10^{6} \quad(n=6)$ and (pre eclamptic) $4.8 \times 10^{7} \pm 4.5 \times 10^{6} \quad(n=4) \quad$ (Fig. 3). The mRNA expression levels of ROCK I and ROCK II were not significantly different between the two vessel types analysed $(P>0.05)$. The CDNA copy numbers for ROCK I were: (normal) $1.3 \times 10^{7} \pm 8.7 \times 10^{5} \quad(n=6)$;

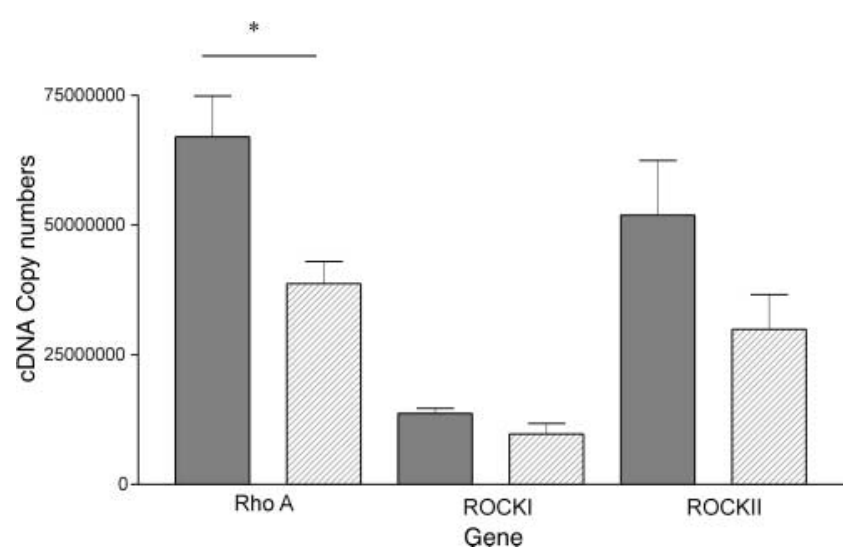

Figure 3 Rho A, ROCK I, ROCK II and $\beta$-actin mRNA expression in human umbilical artery from normal pregnancies $(\mathrm{N} ; n=6)$ and pre eclamptic pregnancies (PET; $n=4$ ) by real-time fluorescence RT-PCR. cDNA copy numbers are shown on the $y$-axis and the genes investigated on the $x$-axis. The histogram depicts Rho A, ROCK I and ROCK II cDNA copy numbers normalised to the housekeeping gene $\beta$ actin. Grey columns represent normal samples. Columns with diagonal grey stripes represent pre eclamptic samples. Vertical error bars represent standard error of the mean (S.E.M.). ${ }^{*} \mathrm{~N}$ vs PET $P<0.05$. 
(pre eclamptic) $1.0 \times 10^{7} \pm 1.9 \times 10^{6} \quad(n=4)$ and for ROCK II were: (normal) $5.2 \times 10^{7} \pm 1.1 \times 10^{7} \quad(n=6)$; (pre eclamptic) $3.0 \times 10^{7} \pm 6.7 \times 10^{5}(n=4)$ (Fig. 3).

\section{Effects of isoprostanes on umbilical artery}

Both 8-iso $\mathrm{PGF}_{2 \alpha}$ and 8-iso $\mathrm{PGE}_{2}$ exerted a significant concentration-dependent vasocontractile effect on human umbilical artery. This is graphically represented as a histograph in Fig. 4 for 8-iso $\mathrm{PGF}_{2 \alpha,}$ and in Fig. 5 for 8-iso $\mathrm{PGE}_{2}$. The MMC effect (in g tension) and the $p D_{2}$ values ( \pm s.E.M.) are detailed in Table 3. Calculated increases in $\mathrm{g}$ tension for control rings and rings exposed to 8-iso $\mathrm{PGF}_{2 \alpha}$ were compared by Student's t-test. Analysis revealed a significant contractile effect at increasing 8-iso $\mathrm{PGF}_{2 \alpha}$ concentrations of $1 \mu \mathrm{mol} \mathrm{I}^{-1}$ $(P<0.01)$ and $10 \mu \mathrm{mol} \mathrm{I}^{-1}(P<0.001)$. Similarly, calculated increases in $g$ tension for control rings and rings exposed to 8-iso $\mathrm{PGE}_{2}$ were compared by Student's $t$ test. Again, analysis revealed a significant contractile effect at increasing 8-iso $\mathrm{PGE}_{2}$ concentrations of $1(P<0.001)$ and $10 \mathrm{molI}^{-1} \quad(P<0.001)$. 8-iso $\mathrm{PGE}_{2}$ induced vasocontractions were significantly greater than those induced by 8 -iso $\mathrm{PGF}_{2 \alpha}(P<0.05)$. There was no significant difference between $p D_{2}(P>0.05)$ values for both compounds.

\section{Effects of rho kinase antagonism on umbilical artery}

8-iso $\mathrm{PGE}_{2}$ induced contractions were significantly antagonised by the specific rho kinase inhibitor $\mathrm{Y}-27632(P<0.01)$. This is demonstrated graphically in Fig. 5. 8-iso $\mathrm{PGF}_{2 \alpha}$ induced contractions were not significantly antagonised ( $P>0.05)$ (Fig. 4). The MMC and $p D_{2}$ values ( \pm s.E.M.) for antagonised 8 -iso $\mathrm{PGF}_{2 \alpha}$

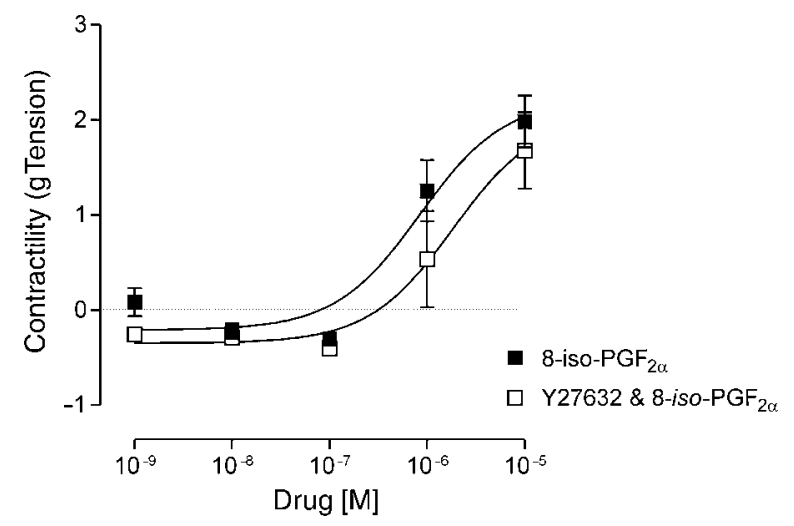

Figure 4 The effects of 8-iso $\mathrm{PGF}_{2 \alpha}$ (alone and following Y-27632 addition) on human umbilical artery tone. The graph depicts the effects of cumulative increases in bath concentration of 8-iso $\mathrm{PGF}_{2 \alpha}(1 \mathrm{nM}-10 \mu \mathrm{M})$ at 20 min intervals. Open squares represent 8-iso $\mathrm{PGF}_{2 \alpha}$ (following $\mathrm{Y}$ 27632 addition) and closed squares represent 8-iso $\mathrm{PGF}_{2 \alpha}$ (alone). Contractility (g Tension) is shown on the $y$-axis, and the concentration of 8iso $\mathrm{PGF}_{2 \alpha}$ is shown on the $x$-axis. Values plotted are means. Vertical error bars represent the standard error of the mean (S.E.M.).

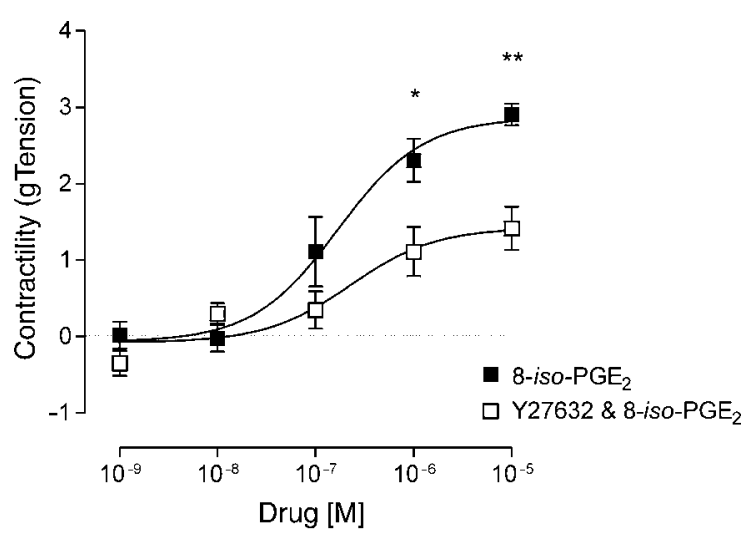

Figure 5 The effects of 8-iso $\mathrm{PGE}_{2}$ (alone and following Y-27632 addition) on human placental artery tone. The graph depicts the effects of cumulative increases in bath concentration of 8-iso $\mathrm{PGE}_{2}(1$ $\mathrm{nM}-10 \mu \mathrm{M})$ at $20 \mathrm{~min}$ intervals. Open squares represent 8-iso $\mathrm{PGE}_{2}$ (following Y-27632 addition) and closed squares represent 8-iso $\mathrm{PGE}_{2}$ (alone). Contractility (g Tension) is shown on the $y$-axis, and the concentration of 8-iso $\mathrm{PGE}_{2}$ is shown on the $x$-axis. Values plotted are means. Vertical error bars represent the standard error of the mean (S.E.M.). * 8-iso $\mathrm{PGE}_{2}$ vs $\mathrm{Y}$-27632 and 8-iso $\mathrm{PGE}_{2}, P<0.05$; ** 8-iso $\mathrm{PGE}_{2}$ vs $\mathrm{Y}-27632$ and 8-iso $\mathrm{PGE}_{2}, P<0.001$.

and 8-iso $\mathrm{PGE}_{2}$ are detailed in Table 3. There was no significant difference in $p D_{2}$ values for antagonised 8-iso $\mathrm{PGF}_{2 \alpha}$ and 8-iso $\mathrm{PGE}_{2}$ in comparison to 8-iso $\mathrm{PGF}_{2 \alpha}$ $(P>0.05)$ and 8-iso $\mathrm{PGE}_{2}(P>0.05)$ alone.

\section{Discussion}

Pre eclampsia is one of the major disorders of obstetrics practice, which contributes to maternal and perinatal morbidity and mortality. An understanding of the biological processes that result in the adverse maternal and foetal consequence is lacking. The factors regulating the foeto-placental vasculature during normal pregnancy, and in pre eclampsia, are poorly understood. The Rho A/Rho kinase system is closely linked to prolonged states of smooth muscle contraction, or vasoconstriction, and is closely linked to hypertensive disorders in animal and human models. For these reasons, we hypothesised that the Rho A/Rho kinase system may be linked to normal foeto-placental

Table 3 Effects of 8-iso $\mathrm{PGE}_{2}$ and 8-iso $\mathrm{PGF}_{2 \alpha}$ alone and antagonised by Y-27632 on human umbilical arterial tone.

\begin{tabular}{lcc}
\hline & \multicolumn{2}{c}{ Umbilical artery } \\
\cline { 2 - 3 } Drug & Contractility (g tension) & $p D_{2}$ \\
\hline 8-iso $\mathrm{PGE}_{2}$ & $2.91 \pm 0.14(n=7)$ & $6.77 \pm 0.13$ \\
8-iso $\mathrm{PGE}_{2}+\mathrm{Y}-27632$ & $1.42 \pm 0.28^{*}(n=6)$ & $6.65 \pm 0.49$ \\
8-iso $\mathrm{PGF}_{2 \alpha}$ & $1.99 \pm 0.27(n=7)$ & $6.07 \pm 0.35$ \\
8-iso PGF & $1.68 \pm 0.40(n=6)$ & $5.73 \pm 0.18$ \\
\hline
\end{tabular}

Values presented are MMC mean \pm s.E.M.

$* P<0.01$ vs 8 -iso $\mathrm{PGE}_{2}$ alone. 
circulatory regulation and the changes that occur in pre eclampsia.

We have demonstrated that the mRNA expression of Rho A appears to be down regulated in umbilical arteries in association with pre eclampsia. An obvious interpretation of this finding is that there is reduced expression, with presumably reduced activity of the Rho A/Rho kinase pathway in these vessels, in association with pre eclampsia, which may facilitate greater vasodilatation or enhanced foetal blood flow. Therefore, these findings imply that Rho A/ROCK does not influence the increased vasoconstriction seen in association with PET. These data are preliminary, and there are limitations in concluding from these findings. The total RNA for these results was extracted from total human umbilical artery preparations, and hence includes the endothelium and the vascular smooth muscle layer. This was the deliberate design of the experiments, as it would have been technically difficult to denude these vessels, and these samples were all snap frozen in the operating theatre from women with pre eclampsia or normal pregnancy. Further attempts to explore this issue, i.e. to evaluate and quantify Rho A/Rho kinase pathway expression or activity in the vascular smooth muscle, would require methods that are not as accurate in terms of quantitation, such as immunohistochemical techniques. The other issue, which needs to be addressed, is that of the protein expression and that would require Western Blotting experiments. However, as a preliminary finding, it is apparent from our experiments that Rho A is downregulated at the mRNA level in total umbilical artery vessels from women with pre eclampsia in comparison to control women with normal pregnancies.

It is evident that isoprostanes contribute significantly to the prolonged vasoconstriction that occurs in pre eclampsia. Using umbilical artery ring preparations, with standard in vitro techniques, we have demonstrated that the two isoprostanes 8-iso $\mathrm{PGE}_{2}$ and 8-iso $\mathrm{PGF}_{2 \alpha,}$ both exert a potent vasoconstrictor effect as has been demonstrated previously (Oliveira et al. 2000). By preincubation with a specific Rho kinase inhibitor, it is clear from our experiments that 8-iso $\mathrm{PGE}_{2}$ is unable to elicit the same response after Rho kinase inhibition, indicative of the fact that the Rho kinase pathway is involved in the vasoconstrictor effect of 8-iso $\mathrm{PGE}_{2}$. These results were not found for the vasoconstrictor of 8-iso $\mathrm{PGF}_{2 \alpha}$. There is no obvious reason why the effects of 8-iso $\mathrm{PGF}_{2 \alpha}$ were apparently different to those of 8-iso $\mathrm{PGE}_{2}$, but it is evident that a different mechanism for 8-iso $\mathrm{PGE}_{2}$ exists, which operates at least in part via the Rho kinase pathway. On speculation, this difference observed in relation to antagonism with Y-27632 can only be due to a relative difference in potencies observed in tissues, whereby 8-iso- $\mathrm{PGE}_{2}$ is more potent (Oliveira et al. 2000, Tazzeo et al. 2003). There are no signalling pathways to our knowledge, known to operate via 8-iso$\mathrm{PGE}_{2}$ and 8-iso- $\mathrm{PGF}_{2 \alpha}$ directly. Finally, a further limitation in interpreting these data relate to the fact that, while the cyclooxygenase pathway was blocked, the lipoxygenase pathway was not.

In summary, these findings highlight the potential importance of the Rho A/Rho kinase pathway in the umbilical artery circulation in normal pregnancy, and raise the question of reduced expression at the mRNA level for Rho A in pre eclampsia. The factors regulating these potential changes require further investigation. Future studies include the assessment of the protein expression of the various components of the Rho A/Rho kinase pathway in normal pregnancy and in pregnancies complicated by pre eclampsia. Finally, from a functional point of view, the vasocontractile effect of 8-iso $\mathrm{PGE}_{2}$, a potent isoprostane linked to pre eclampsia appears to be mediated at least in part via the Rho kinase pathway.

\section{Acknowledgements}

We are grateful to the Medical and Midwifery Staff at University College Hospital Galway for their assistance in patient recruitment and obtaining biopsy specimens. This study was financed by the Health Research Board of Ireland. Presented at the 51st Meeting of the Society for Gynecologic Investigation, Houston, Texas, March 24-27, 2004.

\section{References}

Barden A, Beilin LJ, Ritchie J, Croft KD, Walters BN \& Michael CA 1996 Plasma and urinary 8-iso-prostane as an indicator of lipid peroxidation in pre-eclampsia and normal pregnancy. Clinical Science 91 711-718.

Byrne B \& Morrison JJ 2001 Pre-term birth. In Clinical Evidence, issue 5, pp 996-1010. Ed. S Barton. UK British Medical Journal Publishing Group.

Chitaley K, Weber J \& Webb RC 2001 Rho A/Rho-kinase, vascular changes and hypertension. Current Hypertension Reports 3 139-144.

Chomczynski P 1993 A Reagent for single-step simultaneous isolation of RNA. BioTechniques 15 532-536.

Christman BW 1998 Lipid mediator dysregulation in primary pulmonary hypertension. Chest 114 205S-207S.

Cipollone F, Ciabattoni G, Patrignami P, Pasquale M, Di Gregorio D, Bucciarelli T, Davi G, Cuccurullo F \& Patrono C 2000 Oxidant stress and aspirin-insensitive thromboxane biosynthesis in severe unstable angina. Circulation 102 1007-1013.

Curley M, Morrison JJ \& Smith TJ 2004 analysis of Maxi-K alpha subunit spice variants in human myometrium. Reproductive Biology and Endocrinology 2 67-75.

Dennedy MC, Houlihan DD, McMillan H \& Morrison JJ 2002 Beta2and beta3-adrenoreceptor agonists: human myometrial selectivity and effects on umbilical artery tone. American Journal of Obstetrics and Gynecology 187 641-647.

Fleming SM, O'Gorman T, Finn J, Grimes H, Daly K \& Morrison JJ 2000 Cardiac troponin I in pre-eclampsia and gestational hypertension. British Journal of Obstetrics and Gynaecology 107 1417-1420.

Fox SB \& Khong TY 1990 Lack of innervation of human umbilical cord, An immunohistological and histochemical study. Placenta 11 59-62.

Friel AM, Curley M, Ravikumar N, Smith TJ \& Morrison JJ 2005 Rho $\mathrm{A} /$ Rho Kinase mRNA and Protein Levels in Human Myometrium during Pregnancy and Labor. Journal of Society for Gynecologic Investigation 12 20-27. 
Hisaoka T, Yano M, Ohkusa T, Seutugu M, Ono K, Kohno M, Yamada J, Kobayashi S, Kohno M \& Matsuzaki M 2001 Enhancement of Rho/Rho-kinase system in regulation of vascular smooth muscle contraction in tachycardia-induced heart failure. Cardiovascular Research 49 319-329.

Janssen LJ, Premji M, Netherton S, Coruzzi J, Lu-Chao H \& Cox PG 2001 Vasoconstrictor actions of isoprostanes via tyrosine kinase and Rho kinase in human and canine pulmonary vascular smooth muscles. British Journal of Pharmacology 132 127-134.

Kunihiko I, Akihiro Y \& Koichi S 1999 Major role for the Rhoassociated coiled coil forming protein kinase in G-protein-mediated $\mathrm{Ca}^{2+}$ sensitisation through inhibition of myosin phosphatase in rabbit trachea. British Journal of Pharmacology 128 925-933.

Mallat Z, Philip I, Lebret M, Chatel D, Maclouf J \& Tedgui A 1998 Elevated levels of 8-iso-prostaglandin F2alpha in pericardial fluid of patients with heart failure: a potential role for in vivo oxidant stress in ventricular dilation and progression to heart failure. Circulation 97 1536-1539.

Moran CJ, Friel AM, Smith TJ, Cairns M \& Morrison JJ 2002 Expression and modulation of Rho kinase in human pregnant myometrium. Molecular Human Reproduction 8 196-200.

Oliveira L, Stallwood NA \& Crankshaw DJ 2000 Effects of some isoprostanes on the human umbilical artery in vitro. British Journal of Pharmacology 129 509-514.

Ravikumar N, Houlihan DD \& Morrison JJ 2004 Effects of polyamines on human umbilical artery tone in vitro. Journal of Society for Gynecologic Investigation 11 536-539.

Roberts LJ II \& Morrow JD 2000 Measurement of $\mathrm{F}_{2}$-isoprostanes as an index of oxidative stress in vivo. Free Radicals in Biology and Medicine 28 505-523.
Roberts JM \& Cooper DW 2001 Pathogenesis and genetics of preeclampsia. Lancet 357 53-56.

Somlyo AP \& Somlyo AV 2000 Signal transduction by G-proteins, Rhokinase and protein phosphatase to smooth muscle and non-muscle myosin II. Journal of Physiology 522 177-185.

Staff AC, Halvorsen B, Ranheim T \& Henriksen T 1999 Elevated level of free 8-iso-prostaglandin $\mathrm{F}_{2 \alpha}$ in the decidua basalis of women with preeclampsia. American Journal Obstetrics and Gynecology 181 1211-1215.

Tazzeo T, Miller J \& Janssen LT 2003 Vasoconstrictor responses, and underlying mechanisms, to isoprostanes in human and porcine bronchial arterial smooth muscle. British Journal of Pharmacology 140 759-763.

Uehata M, Ishizaki T, Satoh H, Ono T, Kawahara T \& Morishita T 1997 Calcium sensitisation of smooth muscle mediated by a Rhoassociated protein kinase in hypertension. Nature 389 990-994.

Walker JJ 2000 Pre-eclampsia. Lancet 356 1260-1265.

Walsh SW, Vaughan JE \& Roberts LJ II 2000 Placental isoprostane is significantly increased in preeclampsia. Federation of American Societies for Experimental Biology Journal 14 1289-1296.

Received 17 December 2005

First decision 8 February 2006

Revised manuscript received 21 March 2006

Accepted 5 May 2006 